\title{
Ulnar Neuropathy due to Intraneural Ganglion Cyst of the Ulnar Nerve at the Elbow
}

\author{
Byung-chul Son ${ }^{1,2}$ Jin-gyu Choi ${ }^{1}$ Hak-cheol Ko ${ }^{1}$ \\ ${ }^{1}$ Department of Neurosurgery, Seoul St. Mary's Hospital, College of \\ Medicine, The Catholic University of Korea, Seoul, Republic of Korea \\ ${ }^{2}$ Catholic Neuroscience Institute, College of Medicine, The Catholic \\ University of Korea, Seoul, Republic of Korea
}

\begin{abstract}
Address for correspondence Byung chul Son, MD, PhD, Department of Neurosurgery, Seoul St. Mary's Hospital, Catholic Neuroscience Institute, College of Medicine, The Catholic University of Korea, 222 Banpo-daero, Seocho-gu, Seoul, Republic of Korea 06591 (e-mail: sbc@catholic.ac.kr).
\end{abstract}

\begin{abstract}
Keywords

- cyst

- intraneural ganglion cyst

- ganglion

- ulnar nerve

- ulnar neuropathy

Intraneural ganglion cysts are rare mucinous cyst originating within the epineurium of peripheral nerves. They occur most commonly in the peroneal nerve. However, they have also been described in many nerves in the vicinity of synovial joints. Intraneural ganglion cysts in the upper extremity are rare. Those at the elbow joint comprise only $9 \%$ of intraneural ganglion ever reported.

A 66-year-old and right-handed male patient presented with a sudden onset of righthand weakness. He initially noticed paresthesia with decreased sensation in the lateral two digits and radial palm in his right hand. Physical examination showed thenar muscle atrophy and muscle weakness of the abductor pollicis brevis in the right hand. Preoperative diagnosis of intraneural ganglion cyst was made on the basis of characteristic magnetic resonance imaging (MRI) findings. On exploration, the ulnar nerve was identified proximal to the elbow joint. Its articular branch was addressed and divided from the elbow joint.

To the best of our knowledge, addressing the articular branch connecting the glenohumeral joint for the treatment of intraneural ganglion at the elbow has only been reported twice. We experienced a rare occurrence of intraneural ganglion cyst at the elbow manifesting an ulnar neuropathy. Here, we report intraoperative findings for the articular branch- connected to intraneural ganglion of the ulnar nerve at the elbow. Early diagnosis of intraneural ganglion with precise identification of the pathology and addressing the articular branch with atraumatic dissection of ganglion cyst are essential to achieve successful treatment for this rare lesion.
\end{abstract}

\section{Introduction}

Intraneural ganglion cysts are benign mucinous cysts originating within the epineurium of peripheral nerves. ${ }^{1-4}$ These intraneural ganglion cysts typically result in neurologic deficit due to displacement of nerve fascicles by cyst contents. ${ }^{5-7}$ Synovial cyst or ganglion derived from synovial joints are well known ("ganglion" and "synovial cyst" are used interchangeably in the literature). ${ }^{8}$ Ganglions are cystic structures lined by flat spindle-shaped cells containing mucin or fluid. ${ }^{8,9}$ They occur most commonly in the peroneal nerve. However, they have also been described in many nerves in

received

July 21, 2017

Accepted after revision

October 24, 2017

published online

April 10, 2018 the vicinity of synovial joints. ${ }^{10-13}$ According to a systematic review, ${ }^{5}$ intraneural ganglion cyst in the upper extremity is rare, with vast majority affecting the peroneal nerve. Intraneural ganglion cyst at the elbow comprise only 9\% of intraneural ganglion ever reported..$^{5}$

The pathogenesis of intraneural ganglion cyst has been controversial. ${ }^{5}$ Spinner et al ${ }^{6,7,13}$ have introduced a comprehensive explanation for the pathogenesis of intraneural ganglion cyst. They suggested that a capsular defect or pedicle in a joint might have allowed joint fluid to pass along an articular branch into the parent nerve. Intra-articular pressure then pushes the synovial fluid along the path of least resistance
DOI https://doi.org/

10.1055/s-0038-1639385.

ISSN 2277-954X.
(C)2018 Neurological Surgeons' Society of India
License terms

(®) $\Theta \circledast$ 
and extends the involvement along the nerve and its branches. ${ }^{4,7}$ A unifying articular theory has been introduced and translated directly to clinical outcome. ${ }^{4,7}$ Successful treatment entails disconnection of the cyst from the joint. When this is done, intraneural recurrence can be eliminated. ${ }^{14}$

Although the ulnar nerve at elbow is the second most common site for intraneural ganglions and the prototype for intraneural cysts in the upper extremity, most reports of ulnar intraneural ganglia at the elbow have not recognized the articular branch or its joint connections. ${ }^{14}$ To the best of our knowledge, addressing the articular branch connecting the glenohumeral joint for treating intraneural ganglion cyst at the elbow was only reported by Xu et al. ${ }^{15}$ in 2014 . We experienced a rare occurrence of intraneural ganglion cyst at the elbow manifesting acute ulnar neuropathy. Here, we report intraoperative findings of the articular branch connected to intraneural ganglion of the ulnar nerve at the elbow.

\section{Case Report}

A 66-year-old and right-handed male patient presented with numbness and weakness in his right hand and fingers with duration of 1 month. At the beginning, vague discomfort developed in his hypothenar and the fourth and fifth fingers when he awaked in the morning. In several hours, he noticed paresthesia with decreased sensation in those areas and decreased gripping ability. He has worked actively as an agricultural farmer for the last four decades. He denied any physical trauma or accident possibly affecting his right hand or fingers. His family and medical histories were unremarkable. Considering the relatively sudden onset, he was examined with magnetic resonance imaging (MRI) for the brain. No remarkable finding was found. He was initially treated with nonsteroidal anti-inflammatory drugs and activity modification. However, over the next 1 month, he lost his hand muscles' bulk. Clumsiness of his hand and fingers gradually worsened. He was referred for further evaluation.
His neurologic examination revealed profound weakness of the flexor digitorum profundus (FDP) of the fourth and fifth fingers (grade 3/5) and moderate atrophy of intrinsic muscles of the right hand. Both Froment's and Wartenberg's signs were positive. His sensations to light touch and pinprick were decreased in the little and ulnar aspect of the ring finger. There was no pain (spontaneously or evoked) in association with passive movement of the elbow joint. No Tinel's phenomenon or tenderness overlying the ulnar nerve was observed in the cubital tunnel. Electrophysiologic study demonstrated moderate degree of denervation of ulnar-innervated muscle groups. Because clinical and electrophysiologic findings were consistent with severe ulnar entrapment at the elbow with advanced motor signs, an MRI of the elbow was requested. The MRI of the right elbow showed a long segmental and high signal intensity lesion on T2-weighted images along the course of the ulnar nerve both proximal and distal to the cubital tunnel ( $\boldsymbol{-}$ Fig. 1). The lesion appeared at low signal intensity on T1-weighted images with enhancement after gadolinium (-Fig. 1). The elbow joint showed a prominent degenerative change with partial tear of the medial collateral ligament. The flexor carpi ulnaris showed slight high signal intensity indicating denervation change on T2-weighted images (-Fig. 1). Laboratory examinations including erythrocyte sedimentation rate, C-reactive protein, rheumatoid factor, antinuclear antibody, and creatinine kinase were normal. Considering the course of ulnar nerve palsy and abnormal MRI findings, an exploration of the peroneal nerve was performed.

After releasing Osborne's ligament at the cubital tunnel, the ulnar nerve was found to be swollen with rubbery consistency (-Fig. 2). There was no adhesion or entrapment found within the cubital tunnel. The thickened articular branch was addressed beneath the ulnar nerve at the cubital tunnel (-Fig. 2). It was coagulated and divided. Neurotomy was not performed in the swollen ulnar nerve due to risk of neural injury. In situ decompression of the ulnar nerve
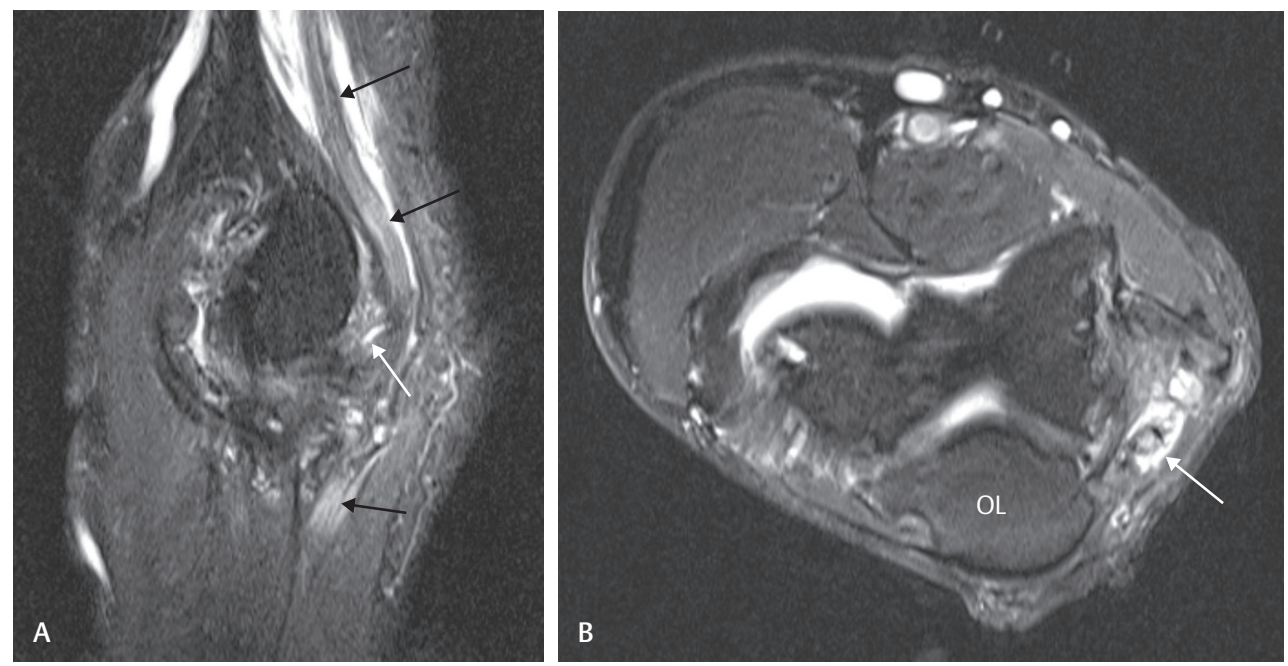

Fig. 1 MRI of intraneural ganglion cyst involving the right ulnar nerve. (A) T2-weighted coronal FSE image with fat suppression showing a tubular cyst (black arrows) circumferentially surrounding the ulnar nerve with connection to the elbow joint (white arrow). (B) T2-weighted axial FSE image with fat suppression showing an intraneural ganglion cyst of the ulnar nerve. FSE image,fast spin-echo image; MRI, magnetic resonance imaging; OL, olecranon. 

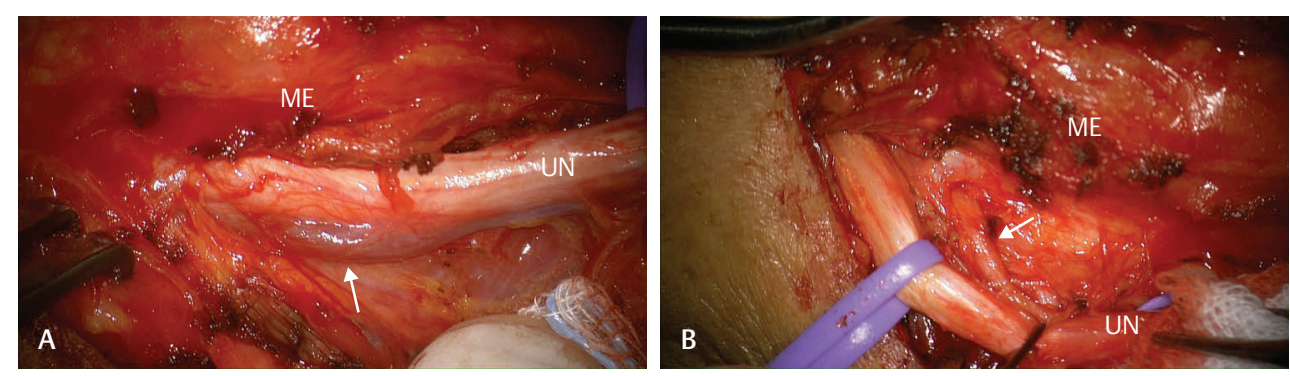

Fig. 2 Intraoperative photographs showing the intraneural ganglion cyst of the ulnar nerve. (A) An intraoperative photograph showing the course of right ulnar nerve after proximal opening of the cubital tunnel. Arrow indicates the extraneural compartment of the intraneural ganglion cyst. The ulnar nerve was swollen. (B) An intraoperative photograph showing the articular branch (arrow) connecting the joint. ME, medial epicondyle; UN, ulnar nerve.

was performed. Postoperative course was uneventful. The pinch and grip strength were gradually recovered with minimal paresthesia in the fifth finger and hypothenar area at 3 months postoperatively. Clawing and Waternberg signs were minimally present in the fifth finger. No paresthesia was felt at 6 months postoperatively. The patient's condition was stable without any recurrent symptom at follow-up of 12 months at an outpatient clinic.

\section{Discussion}

\section{Intraneural Ganglion Cysts}

The etiology of intraneural ganglion cysts has been poorly understood. Multiple surgical treatments strategies have been developed for intraneural ganglion cyst that has an estimated recurrence rate of 11 to $30 \% .^{5}$ Three theories has been suggested, including degenerative theory, ${ }^{10}$ tumoral theory, ${ }^{16}$ and articular (synovial) theory. ${ }^{4,7}$ Since the first case report of an intraneural ganglion of the common peroneal nerve in 1921 , such lesion has been reported at a variety of other sites, including the ulnar, radial, median, sciatic, tibial, and posterior interosseous nerves, all of which tend to occur adjacent to the joint or bursa. $4,5,7$

Considering that these universal occurrence of intraneural ganglia near joints and their tendency to extend proximally, the high percentage of preceding trauma of knee or superior tibiofibular joint abnormalities, the predominance of deep peroneal nerve dysfunction sparing of superficial peroneal nerve, and frequent finding of a pedicle to the superior tibiofibular joint, Spinner et al. ${ }^{4,11,14}$ have suggested the unifying articular (synovial) theory as the etiology for intraneural ganglion cysts. The core principle involved in the formation of these cysts is a joint connection via an articular branch. ${ }^{17}$ This describes that the intraneural ganglion cysts is arising from a neighboring synovial joint and propagating through a capsular rent into an articular branch and then the proximal, parent nerve. Cyst (joint) fluid follows the path of least resistance. The shape and size of the cyst depend on pressure and pressure fluxes. ${ }^{12,14,15}$ Based on the prototype of the intraneural ganglion cyst of the peroneal nerve, this unifying articular theory has been substantiated and repeatedly replicated by others in recent years. ${ }^{18-20}$ It has been extrapolated to intraneural ganglion cysts involving other nerves in both the upper and lower extremities. ${ }^{5}$

\section{Intraneural Ganglion Cysts of the Ulnar Nerve and Treatment}

Although the incidence of intraneural ganglion cysts involving the ulnar nerve has been estimated as $9 \%$ of all intraneural ganglions reported, the report specifically documenting the connection of the joint with the articular branch of the ulnar nerve is rare. It was summarized in - Table 1. In the diagnosis of intraneural ganglion cysts, high-resolution MRI is essential for diagnosis and morphologic classification of intraneural ganglion cysts. ${ }^{11}$ Two imaging signs, the signet ring $^{13}$ and the transverse limb signs ${ }^{6}$ have been suggested to be extremely robust in differential diagnosis of intraneural ganglion cysts and more common extraneural variants. ${ }^{21}$ Similar MRI findings of the joint connection of the intraneural ganglion of the ulnar nerve have been demonstrated by Spinner et al. ${ }^{14}$ In the current case, typical MRI findings of intraneural ganglion cysts akin to those occurring in peroneal nerves were observed (-Fig. 2).

Treatment of progressive nerve palsy due to intraneural ganglion is early surgery. ${ }^{22}$ If surgical treatment is delayed, intraneural growth and invasion may cause irreversible axonal damage and the outcome of foot drop is poor. ${ }^{22}$ Young age, the absence of nerve damage, and the duration of symptoms have been reported to be associated with clinical outcomes. ${ }^{22-25}$ Patients who had foot drop for less than 4 months have shown favorable outcomes. ${ }^{22}$ If there is denervation of the tibialis anterior muscle in the preoperative electromyogram (EMG) examination, complete resolution of peroneal palsy is less likely. ${ }^{22}$

In treatment of intraneural ganglion cyst involving the ulnar nerve, the same principle should be applied to those occurring in the ulnar nerves. The surgical procedure involves exploration and decompression of involved nerves. ${ }^{12}$ However, techniques for surgical treatment of intraneural ganglion cysts have been controversial. ${ }^{23}$ In line with the articular theory, ${ }^{4,9,22}$ Spinner et $\mathrm{a}^{25}$ have suggested treating the articular branch connection and/or the joint. They suggested the four D technique: dissection of the nerve, disarticulation of the tibiofibular joint, decompression of the cyst, and disconnection of the articular branch. Failure to disconnect the articular branch or treat the joint pathology has been found to be a statistically significant factor for recurrence as high as 30\%., $4,14,25$ In addition, treatment of the superior tibiofibular joint (STFJ), the origin of the ganglion cyst, has become a critical part of surgery for STFJ-associated intraneural cyst. ${ }^{3}$ According to 
Table 1 Summary of case reports demonstrating intraneural ganglion cyst of the ulnar nerve with addressing the articular branches

\begin{tabular}{|c|c|c|c|c|c|c|c|}
\hline Authors, year & Study & $\begin{array}{l}\text { Number } \\
\text { of cases }\end{array}$ & $\begin{array}{l}\text { Presenting } \\
\text { symptoms } \\
\text { and signs }\end{array}$ & $\begin{array}{l}\text { Diagnostic } \\
\text { tools of IGC }\end{array}$ & Joint connected & $\begin{array}{l}\text { Treatment } \\
\text { involving } \\
\text { articular } \\
\text { branch }\end{array}$ & $\begin{array}{l}\text { Result, follow-up } \\
\text { period }\end{array}$ \\
\hline $\begin{array}{l}\text { Okada et al, }{ }^{19} \\
2011\end{array}$ & Case report & 1 & $\begin{array}{l}\text { Soft tissue } \\
\text { mass, } \\
\text { numbness, } \\
\text { sensory deficit, } \\
\text { and atrophy }\end{array}$ & MRI & $\begin{array}{l}\text { Distal radioulnar } \\
\text { joint }\end{array}$ & Yes & $\begin{array}{l}\text { Good, no } \\
\text { recurrence, } \\
18 \text { mo }\end{array}$ \\
\hline $\begin{array}{l}\text { Weyns et al, }{ }^{20} \\
2012\end{array}$ & Case series & 5 & $\begin{array}{l}\text { Weakness, } \\
\text { hand atrophy }\end{array}$ & $\begin{array}{l}\text { Ultrasound/ } \\
\text { MRI }\end{array}$ & $\begin{array}{l}\text { Guyon canal (4) } \\
\text { Cubital tunnel } \\
(1)\end{array}$ & Yes & $\begin{array}{l}\text { Complete } \\
\text { recovery }(4 / 5), \\
6-13 \text { mo }\end{array}$ \\
\hline $\begin{array}{l}\text { Xu et al, }{ }^{15} \\
2014\end{array}$ & Case report & 1 & $\begin{array}{l}\text { Numbness, } \\
\text { weakness, } \\
\text { soft tissue } \\
\text { mass }\end{array}$ & MRI & Cubital tunnel & Yes & $\begin{array}{l}\text { Significant } \\
\text { improvement, } \\
3 \text { mo }\end{array}$ \\
\hline $\begin{array}{l}\text { Current case, } \\
2017\end{array}$ & Case report & 1 & $\begin{array}{l}\text { Sudden } \\
\text { weakness, } \\
\text { numbness, } \\
\text { intrinsic } \\
\text { muscle atrophy }\end{array}$ & MRI & Cubital tunnel & Yes & $\begin{array}{l}\text { Significant } \\
\text { improvement, } \\
12 \text { mo }\end{array}$ \\
\hline
\end{tabular}

Abbreviations: IGC, intraneural ganglion; MRI, magnetic resonance imaging.

Desy et $a{ }^{5}{ }^{5}$ addressing the joint connection and/or joint pathology might even obviate the need for cyst/nerve decompression. If cyst decompression is attempted, simple cyst incision and evacuation of the mucinous fluid are recommended to avoid iatrogenic nerve injury instead of using more radical procedure, such as full cyst excision. ${ }^{25}$

In the current case, we identified and divided the articular branch while the swollen ulnar nerve was left untouched because an identifiable dissection plane could not be searched during operation. Without direct manipulation of the intraneural ganglion cyst in the ulnar nerve, we could achieve progressive improvement of preoperative neurologic deficit. This case supports the (synovial) articular theory as the pathology of intraneural ganglion cysts.

\section{Conclusion}

A rare case of intraneural ganglion cyst involving the ulnar nerve is reported here. Findings of MRI and the articular branch connecting the joint support the (synovial) articular theory in the pathophysiology of intraneural ganglion cyst. Early diagnosis, detailed MRI examination, and addressing the articular branch of the ulnar nerve are important to achieve successful treatment for rare intraneural ganglion cyst.

\section{Note}

All procedures performed in current study were in accordance with the ethical standards of the institutional and/or national research committee and with the 1964 Helsinki declaration and its later amendments or comparable ethical standards. This study was approved by our university'sinstitutional review board. The ethical reference number is KC17ZESI0096.

\section{Funding}

None.

\section{Conflict of Interest}

None.

\section{References}

1 Allieu PY, Cenac PE. Peripheral nerve mucoid degeneration of the upper extremity. J Hand Surg Am 1989;14(2 Pt 1):189-194

2 Giele H, Le Viet D. Intraneural mucoid cysts of the upper limb. J Hand Surg [Br] 1997;22(6):805-809

3 Naam NH, Carr SB, Massoud AH. Intraneural Ganglions of the hand and wrist. J Hand Surg Am 2015;40(8):1625-1630

4 Spinner RJ, Atkinson JL, Tiel RL. Peroneal intraneural ganglia: the importance of the articular branch. A unifying theory. J Neurosurg 2003;99(2):330-343

5 Desy NM, Wang H, Elshiekh MA, et al. Intraneural ganglion cysts: a systematic review and reinterpretation of the world's literature. J Neurosurg 2016;125(3):615-630

6 Spinner RJ, Desy NM, Amrami KK. The cystic transverse limb of the articular branch: a pathognomonic sign for peroneal intraneural ganglia at the superior tibiofibular joint. Neurosurgery 2006;59:157-166

7 Spinner RJ, Scheithauer BW, Amrami KK. The unifying articular (synovial) origin of intraneural ganglia: evolution-revelation-revolution. Neurosurgery 2009;65(4, Suppl):A115-A124

8 Capek S, Koutlas IG, Strasia RP, Amrami KK, Spinner RJ. An inferior alveolar intraneural cyst: a case example and an anatomical explanation to support the articular theory within cranial nerves. J Neurosurg 2015;122(6):1433-1437

9 Janzen DL, Peterfy CG, Forbes JR, Tirman PF, Genant HK. Cystic lesions around the knee joint: MR imaging findings. AJR Am J Roentgenol 1994;163(1):155-161

10 Poppi M, Nasi MT, Giuliani G, Acciarri N, Montagna P. Intraneural ganglion of the peroneal nerve: an unusual presentation. Case report. Surg Neurol 1989;31(5):405-406 
11 Spinner RJ, Amrami KK, Wolanskyj AP, et al. Dynamic phases of peroneal and tibial intraneural ganglia formation: a new dimension added to the unifying articular theory. J Neurosurg 2007;107(2):296-307

12 Spinner RJ, Carmichael SW, Wang H, Parisi TJ, Skinner JA, Amrami KK. Patterns of intraneural ganglion cyst descent. Clin Anat 2008;21(3):233-245

13 Spinner RJ, Luthra G, Desy NM, Anderson ML, Amrami KK. The clock face guide to peroneal intraneural ganglia: critical "times" and sites for accurate diagnosis. Skeletal Radiol 2008;37(12):1091-1099

14 Spinner RJ, Harish S, Amrami KK. An historical perspective on ulnar intraneural ganglion cysts and their joint origins. Hand (NY) 2014;9(3):395-398

$15 \mathrm{Xu}$ Q, Chen Z, Dellon AL, Zhang F. Microsurgical principles related to excision of intraneural ganglion at the elbow. Hand (NY) 2014;9(2):214-216

16 Jenkins SA. Solitary tumours of peripheral nerve trunks. J Bone Joint Surg Br 1952;34(b):401-11

17 Elangovan S, Odegard GM, Morrow DA, Wang H, Hébert-Blouin MN, Spinner RJ. Intraneural ganglia: a clinical problem deserving a mechanistic explanation and model. Neurosurg Focus 2009;26(2):E11

18 Isaacs AM, Midha R, Desy NM, Amrami KK, Spinner RJ. The mechanism underlying combined medial and lateral plantar and tibial intraneural ganglia in the tarsal tunnel. Acta Neurochir (Wien) 2016;158(11):2225-2229
19 Okada M, Sakaguchi K, Oebisu N, Takamatsu K, Nakamura H. A ganglion within the ulnar nerve and communication with the distal radioulnar joint via an articular branch: case report. J Hand Surg Am 2011;36(12):2024-2026

20 Weyns F, Bringmans T, Vandevenne J, et al. Peripheral neuropathy caused by joint-related cysts: a review of 17 cases. Acta Neurochir (Wien) 2012;154(10):1741-1753

21 Prasad NK, Desy NM, Howe BM, Amrami KK, Spinner RJ. Subparaneurial ganglion cysts of the fibular and tibial nerves: a new variant of intraneural ganglion cysts. Clin Anat 2016;29(4):530-537

22 Muramatsu K, Hashimoto T, Tominaga Y, Tamura K, Taguchi T. Unusual peroneal nerve palsy caused by intraneural ganglion cyst: pathological mechanism and appropriate treatment. Acta Neurochir (Wien) 2013;155(9):1757-1761

23 Sobol GL, Lipschultz TM. Successful surgical treatment of an intraneural ganglion of the common peroneal nerve. Am J Orthop 2015;44(4):E123-E126

24 Lowenstein J, Towers J, Tomaino MM. Intraneural ganglion of the peroneal nerve: importance of timely diagnosis. Am J Orthop 2001;30(11):816-819

25 Spinner RJ, Desy NM, Rock MG, Amrami KK. Peroneal intraneural ganglia. Part II. Lessons learned and pitfalls to avoid for successful diagnosis and treatment. Neurosurg Focus 2007;22(6):E27 